\title{
SUPPLEMENTAL EFFECT OF LYSINE ON GROWTH DEPRESSION OF RATS FED WHEAT GLUTEN DIETS CONTAINING EXCESSIVE AMOUNT OF SOME INDIVIDUAL AMINO ACIDS
}

\author{
Keiichiro Muramatsu and Kyosuke Sakurai ${ }^{1}$ \\ Laboratory of Food and Nutrition, Department of Agricultural Chemistry, \\ Faculty of Agriculture, Shizuoka University, Shizuoka
}

(Received October 1, 1973)

\begin{abstract}
The effects of lysine supplementation on the growth depression causes by the excessive addition of some individual amino acids to a wheat gluten diet in which lysine is the first-limiting amino acid were studied. Male weanling rats were fed $11.6 \%$ wheat gluten (equivalent to the $\mathrm{N}$ content of $10 \%$ casein) diets containing $5.0 \%$ of single amino acids, L-arginine $\cdot \mathrm{HCl}$, L-tryptophan, L-phenylalanine, L-methionine and Ltyrosine, with or without $0.6 \%$ of L-lysine $\mathrm{HCl}$ for 3 weeks. The growth retardation produced by the excess arginine was reversed by the supplement of lysine, but the adverse effects caused by the excessive addition of the other amino acids were not alleviated. The moderate elevations of arginine and lysine levels in blood plasma produced by excess arginine diet did not altered by the supplemental lysine. In contrast, the plasma levels of phenylalanine, tyrosine, tryptophan and methionine elevated by the excessive feeding of corresponding amino acid were decreased fairly by the supplement of lysine. The activities of liver arginase did not changed appreciably by the addition of excess arginine and the supplemental lysine. It is suggested that the decrease in growth when excess arginine is added to lysine-deficient diet causes the reduction of lysine utilization and increases need for lysine.
\end{abstract}

The severity of the growth depression occurs in rats fed a low protein diet containing excessive amount of single L-amino acids is dependent not only upon the kind of amino acid supplemented (1-3) and the protein content in diet (2-4) but also upon the source of dietary protein $(2,5)$.

Previous study (5) showed that a) the growth-depressing effect of individual amino acid added to a wheat gluten diet is generally severer than those added to

1 村松敬一郎, 桜井恭助 
casein and egg albumin diets; b) regardless of the protein source, excess methionine, phenylalanine and tyrosine are more toxic than those of other amino acids; and in addition c) when the wheat gluten was used, tryptophan and arginine also cause severe growth depression, although arginine only causes a slight growth depression when casein or egg albumin was supplied as the protein source. Why does excess arginine depress the growth of rats when added to a wheat gluten diet? What effect does lysine, which is the first limiting amino acid in the wheat gluten, have on the adverse effect of excess amino acids?

To elucidate these problems, the present study was undertaken to investigate the effect of lysine supplement on the growth depression which produced in rats fed wheat gluten diets containing excessive amount of single L-arginine, L-tryptophan, L-phenylalanine, L-tyrosine and L-methionine.

\section{EXPERIMENTAL}

Male weanling rats (55 to $58 \mathrm{~g}$ ) of Donryu strain were separated into twelve groups of 4 animals each. The animals were housed individually in a temperature- and light-controlled room and were allowed food and water ad libitum for 3 weeks. The basal diet contained $11.6 \%$ wheat gluten ${ }^{2}$ (equivalent to a nitrogen content of $10 \%$ casein) $; 5.0 \%$ soybean oil $; 5.0 \%$ salt mixture ${ }^{3} ; 1.0 \%$ vitamin mixture $30.1 \%$ choline chloride; $2.0 \%$ cellulose powder and $\alpha$-potato starch to make $100 \%$. Vitamin A (2,000 IU) and $\mathrm{D}_{2}(200 \mathrm{IU})$ were also added. ${ }^{4}$ Additions of $5.0 \%$ of single L-arginine $\cdot \mathrm{HCl}$, L-tryptophan, L-phenylalanine, L-methionine and L-tyrosine, with or without $0.6 \%$ of L-lysine. HCL were made at the expense of $\alpha$-starch. This supplemental level of lysine to the basal diet was adequate for the requirement of lysine (6). When the experimental diet containing $5.0 \%$ arginine $\cdot \mathrm{HCl}$ was prepared, $2.0 \%$ of sodium bicarbonate was included at the replacement of cellulose powder. Body weights were recorded daily and total dry food consumptions were measured. At the end of the experimental period, animals were killed by decapitation $2 \mathrm{hr}$ after the final feeding. The blood was centrifuged in heparinized tubes, and equal volumes of plasma were pooled from each rat. Plasma was deproteinized with equal volumes of $3 \%$ sulfosalicylic acid, and the free amino acid concentrations were determined as described previously (5) using an automatic amino acid analyzer. ${ }^{5}$

The decapitated animals were perfused in situ with ice-cold $0.9 \%$ saline, then the livers were excised, weighed and homogenized in two volumes of ice-cold $0.14 \mathrm{M} \mathrm{KCl}$. Protein, RNA and DNA contents of the liver homogenates were determined by the procedure used earlier (3). Liver arginase activity in the homogenates was assayed by the same manner as reported previously (7), and the

\footnotetext{
${ }^{2}$ Shin-shin Food Industry Co., Ltd., Tokyo.

3 Tanabe Amino Acid Research Foundation, Osaka.

${ }^{4}$ Chocora A, Eizai Co., Ltd., Tokyo.

5 JEOL Model JLC-5AH, JEOL Co., Ltd., Tokyo.
} 
activity was expressed as $\mu$ mole of produced urea per $\mathrm{g}$ of wet liver per hour.

\section{RESULTS}

The growth response curves of rats fed the diets containing excessive amount of some individual amino acids, with or without lysine supplement are shown in Fig. 1.

Although rats fed the basal $(11.6 \%$ wheat gluten) diet grew very slowly, the supplement of $0.6 \%$ lysine $\cdot \mathrm{HCl}$ to the diet produced a significant improvement in weight gain. As might be expected, the addition of $5.0 \%$ of single arginine, tryptophan, phenylalanine, methionine, and tyrosine to the basal diet caused growth depression to varying degrees. The rats receiving excess arginine diet resulted in growth retardation and maintained the initial body weight at the end of the feeding period, whereas animals fed excess methionine diet caused most significant reduction in weight where the remarkable weight loss occurred during the first few days of the feeding period after which rats remained the weight.

The growth retardations caused by excess tryptophan, phenylalanine, and tyrosine were graded between those caused by arginine and methionine. These data agree closely with the results of previous report (3).

When rats were fed the excess arginine diet supplemented with lysine, the growth rate was considerably increased, and the weight gain at the end of the feeding period reached $80 \%$ of the basal diet supplemented with lysine. The difference between both groups was not significant (see Table 1).

In contrast, the supplement of lysine to the excess tryptophan, phenylalanine, methionine and tyrosine diets failed to improve the growth rate, though the lysine addition to the excess phenylalanine diet showed a tendency to somewhat alleviate the growth depression, but did not statistical significances. In spite of whether lysine was supplemented to the excess tyrosine diet or not, the animals developed external pathological lesions, and all rats fed the diet supplemented with lysine died within 8 to 15 days, while all animals fed excess tyrosine diet died within 15 to 20 days. Thus, the supplement of lysine to the excess tyrosine diet rather shortened the survival time of animals. In earlier experiment (5), when rats were fed excess tyrosine diet, two out of seven animals survived during the 3-week period. This discrepancy is probably due to the fact that the rats used weighed somewhat less than those of the previous experiment.

The data of food intake, liver weight and some liver compositions are presented in Table 1. Food intake of rats fed the excess arginine diet supplemented with lysine increased significantly more than that of the animals fed the excess arginine diet without lysine, whereas in rats with the supplement of lysine to the excess tryptophan, phenylalanine and methionine diets, the food intake did not increase over the values of diets without lysine, respectively. Thus, a close relationship between growth depression and decrease of food intake was indicated. 

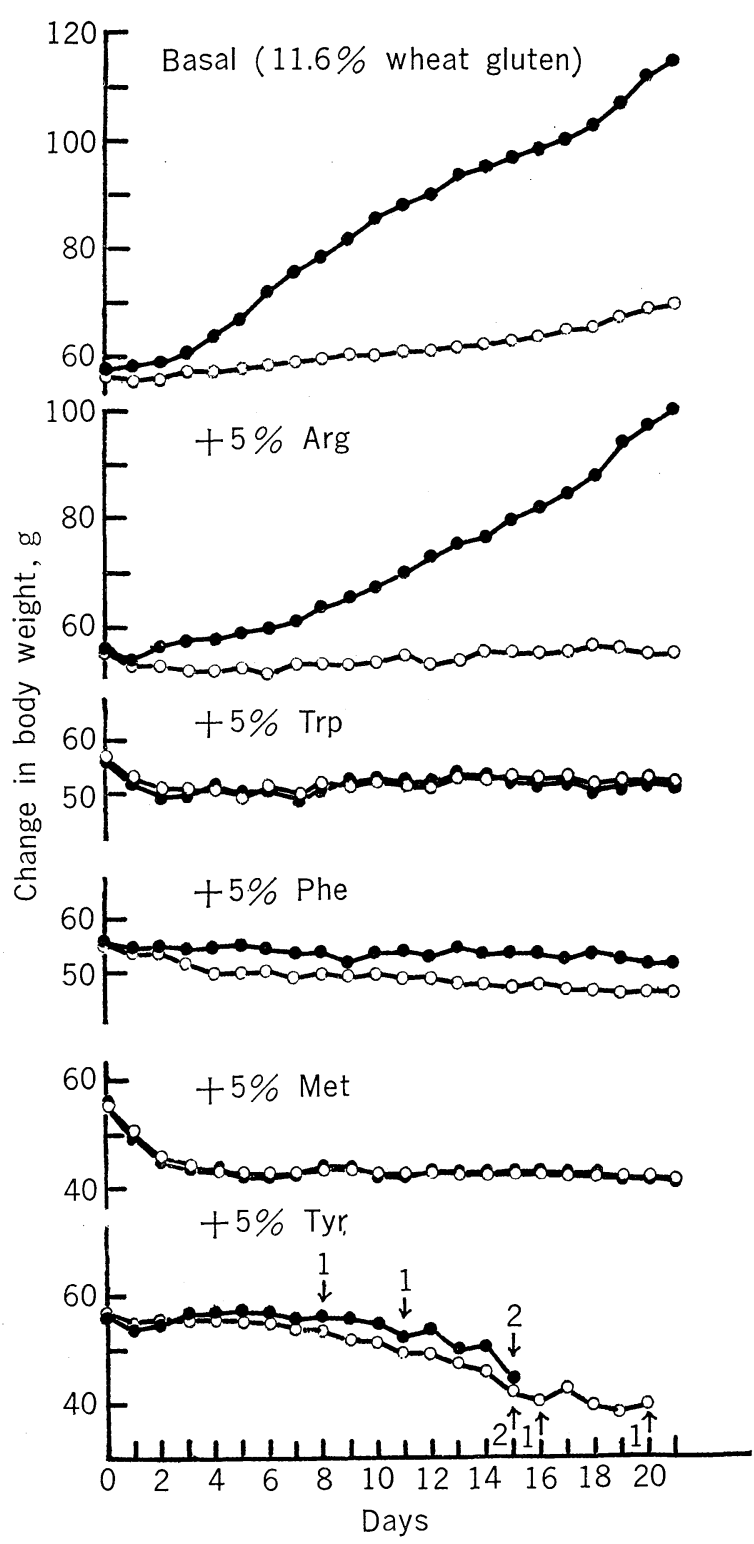

Fig. 1. Effect of lysine supplement on growth of rats fed wheat gluten diets containing excessive amount of single arginine, tryptophan, phenylalanine, methionine, and tyrosine. Each point represents the average body weight of four rats, except for a part of excess tyrosine groups. $\quad$, with $0.6 \%$ lysine $\cdot \mathrm{HCl}$; $\mathrm{O}$, without $0.6 \%$ lysine; $\downarrow$, dead day and number of animals. 
Table 1. Body weight gain, food intake, liver weight, liver DNA, protein, and RNA in rats fed wheat gluten diets containing excessive amount of single arginine, tryptophan, phenylalanine and methionine, with supplemented or unsupplemented lysine.

\begin{tabular}{ccccc}
\hline $\begin{array}{c}\text { Addition to basal } \\
(11.6 \% \text { wheat gluten }) \\
\text { diet }\end{array}$ & $\begin{array}{c}\text { Body weight } \\
\text { gain } \\
(\mathrm{g} / 3 \text { weeks })\end{array}$ & $\begin{array}{c}\text { Food intake } \\
(\mathrm{g} / 3 \text { weeks })\end{array}$ & $\begin{array}{c}\text { Liver weight } \\
(\mathrm{g})\end{array}$ & $\begin{array}{c}\text { DNA } \\
(\mathrm{mg} / \text { liver })\end{array}$ \\
\hline $\begin{array}{cccc}\text { None (control) } \\
+0.6 \% \mathrm{Lys} \cdot \mathrm{HCl}\end{array}$ & $8.7 \pm 1.1^{\mathrm{a}}$ & $147 \pm 6$ & $2.4 \pm 0.1$ & $7.8 \pm 0.3$ \\
$+5 \% \mathrm{Arg} \cdot \mathrm{HCl}$ & $0.2 \pm 1.4$ & $121 \pm 2$ & $2.5 \pm 0.6$ & $7.8 \pm 0.4$ \\
$+5 \% \mathrm{Arg} \cdot \mathrm{HCl}+0.6 \% \mathrm{Lys} \cdot \mathrm{HCl}$ & $44.5 \pm 3.2^{\mathrm{d}}$ & $195 \pm 8^{\mathrm{e}}$ & $3.8 \pm 0.2^{\mathrm{e}}$ & $10.0 \pm 0.8^{\mathrm{d}}$ \\
$+5 \% \mathrm{Trp}$ & $-4.6 \pm 0.3$ & $104 \pm 3$ & $2.0 \pm 0.1$ & $6.4 \pm 0.3$ \\
$+5 \%$ Trp $+0.6 \% \mathrm{Lys} \cdot \mathrm{HCl}$ & $-3.7 \pm 3.6$ & $100 \pm 8$ & $1.9 \pm 0.2$ & $7.0 \pm 0.3$ \\
$+5 \% \mathrm{Phe}$ & $-11.6 \pm 0.7$ & $96 \pm 3$ & $2.2 \pm 0.1$ & $7.8 \pm 0.5$ \\
$+5 \% \mathrm{Phe}+0.6 \% \mathrm{Lys} \cdot \mathrm{HCl}$ & $-5.2 \pm 4.8^{\mathrm{f}}$ & $105 \pm 5$ & $2.4 \pm 0.2$ & $8.8 \pm 0.7$ \\
$+5 \% \mathrm{Met}$ & $-15.5 \pm 2.4$ & $81 \pm 6$ & $1.9 \pm 0.2$ & $6.7 \pm 0.2$ \\
$+5 \% \mathrm{Met}+0.6 \% \mathrm{Lys} \cdot \mathrm{HCl}$ & $-15.1 \pm 0.8$ & $72 \pm 3$ & $1.8 \pm 0.1$ & $7.5 \pm 0.3$ \\
\hline
\end{tabular}

\begin{tabular}{|c|c|c|c|c|}
\hline \multirow{2}{*}{$\begin{array}{l}\text { Addition to basal } \\
\text { (11.6\% wheat gluten) } \\
\text { diet }\end{array}$} & \multicolumn{2}{|c|}{ Protein } & \multicolumn{2}{|c|}{ RNA } \\
\hline & (mg/liver) & $\begin{array}{c}\text { (Protein/ } \\
\text { DNA) }\end{array}$ & (mg/liver) & (RNA/DNA) \\
\hline None (control) & $279 \pm 10$ & $36 \pm 2$ & $26 \pm 1$ & $3.3 \pm 0.2$ \\
\hline$+0.6 \%$ Lys $\cdot \mathrm{HCl}$ & $796 \pm 52^{c}$ & $62 \pm 2^{c}$ & $60 \pm 6^{b}$ & $4.6 \pm 0.3^{b}$ \\
\hline$+5 \% \mathrm{Arg} \cdot \mathrm{HCl}$ & $285 \pm 34$ & $31 \pm 2$ & $22 \pm 3$ & $2.3 \pm 0.4$ \\
\hline$+5 \% \mathrm{Arg} \cdot \mathrm{HCl}+0.6 \% \mathrm{Lys} \cdot \mathrm{HCl}$ & $534 \pm 29^{d}$ & $54 \pm 4^{\mathrm{d}}$ & $38 \pm 1^{\mathrm{e}}$ & $3.8 \pm 0.4^{\mathrm{d}}$ \\
\hline$+5 \% \operatorname{Trp}$ & $255 \pm 14$ & $40 \pm 2$ & $18 \pm 2$ & $2.8 \pm 0.2$ \\
\hline$+5 \% \operatorname{Trp}+0.6 \%$ Lys $\cdot \mathrm{HCl}$ & $320 \pm 20$ & $46 \pm 1$ & $20 \pm 1$ & $2.8 \pm 0.1$ \\
\hline$+5 \% \mathrm{Phe}$ & $306 \pm 20$ & $40 \pm 3$ & $26 \pm 1$ & $3.4 \pm 0.2$ \\
\hline$+5 \%$ Phe $+0.6 \%$ Lys $\cdot \mathrm{HCl}$ & $368 \pm 53$ & $41 \pm 3$ & $26 \pm 4$ & $3.2 \pm 0.6$ \\
\hline$+5 \%$ Met & $281 \pm 26$ & $42 \pm 3$ & $21 \pm 2$ & $3.1 \pm 0.2$ \\
\hline$+5 \%$ Met $+0.6 \%$ Lys $\cdot \mathrm{HCl}$ & $312 \pm 56$ & $42 \pm 2$ & $19 \pm 1$ & $2.5 \pm 0.2$ \\
\hline
\end{tabular}

a Mean \pm SE. for four rats.

b, c Difference between control and basal plus lysine groups, $p<0.05$ and $p<0.01$, respectively.

d Difference between basal plus lysine and basal plus arginine plus lysine groups was not significant $(p<0.05)$.

e Difference between basal plus lysine and basal plus arginine plus lysine groups, $p<0.05$.

f Difference between basal plus phenylalanine and basal plus phenylalanine plus lysine groups was not significant $(p<0.05)$.

Liver weight, liver total DNA, protein and RNA contents, protein/DNA and RNA/DNA ratios of rats fed excess arginine diet supplemented with lysine were significantly higher than those of animals receiving excess arginine diet, but when rats were fed the excess tryptophan, phenylalanine and methionine diets, these values were unaffected by the supplement of lysine to the diets, though the total DNA and protein contents tended to be higher. 


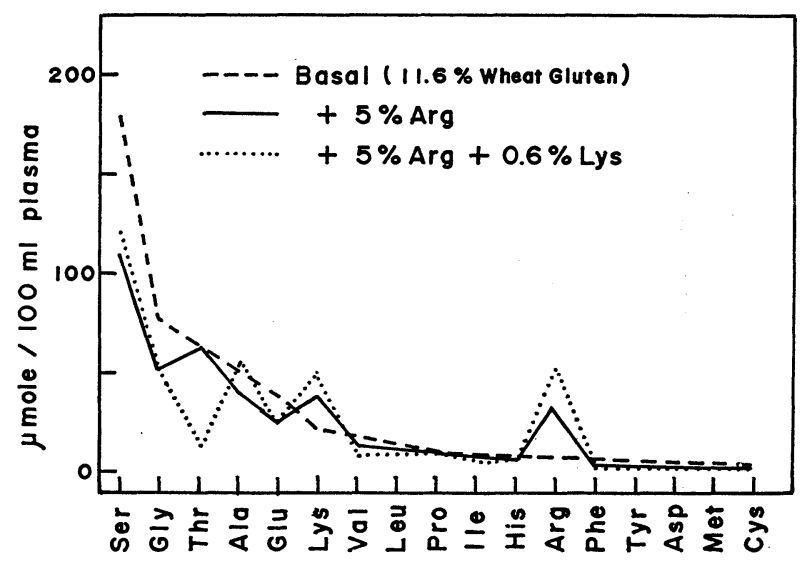

Fig. 2. Plasma amino acid patterns in rats fed the basal (11.6\% wheat gluten), basal plus $5 \%$ arginine $\cdot \mathrm{HCl}$, and basal plus $5 \%$ arginine $\cdot \mathrm{HCl}$ plus $0.6 \%$ lysine $\cdot \mathrm{HCl}$ diets, respectively. Analysis was performed on a pooled sample from four rats.

The free amino acid patterns of blood plasma are shown in Fig. 2. The amino acid pattern of rats fed the excess arginine diet resembled the pattern of animals fed the excess arginine diet supplemented with $0.6 \%$ lysine $\cdot \mathrm{HCl}$, except the threonine concentration. In agreement with the results reported previously (5), the addition of excess arginine to the wheat gluten diet produced the elevation of arginine and lysine levels in plasma. Furthermore, the supplement of lysine to the excess arginine diet tended to result in increases of arginine and lysine levels in plasma. The decline of plasma threonine concentration in animals fed diets supplemented with lysine was consistent with the results of previous observations $(6,8)$.

In line with the previous results (5), the plasma phenylalanine and tyrosine levels in rats fed the excess phenylalanine diet were elevated (65 and $140 \mu$ mole per $100 \mathrm{ml}$ of plasma, respectively), but when lysine was supplemented to the diet the plasma phenylalanine and tyrosine levels were decreased ( 4 and $48 \mu$ mole per

Table 2. Liver arginase activities in rats fed the basal (11.6\% wheat gluten), basal plus $0.6 \%$ lysine $\cdot \mathrm{HCl}$, basal plus $5.0 \%$ arginine $\cdot \mathrm{HCl}$, and basal plus $5.0 \%$ arginine $\cdot \mathrm{HCl}$ plus $0.6 \%$ lysine $\cdot \mathrm{HCl}$ diets, respectively.

\begin{tabular}{cc}
\hline $\begin{array}{c}\text { Addition to basal } \\
(11.6 \% \text { wheat gluten }) \text { diet }\end{array}$ & $\begin{array}{c}\text { Liver arginase } \\
(\mu \text { mole urea/hr/g liver })\end{array}$ \\
\hline None (control) & $14,200 \pm 710^{\mathrm{a}}$ \\
$+0.6 \% \mathrm{Lys} \cdot \mathrm{HCl}$ & $11,350 \pm 830^{\mathrm{b}}$ \\
$+5.0 \% \mathrm{Arg} \cdot \mathrm{HCl}$ & $19,320 \pm 4,580^{\mathrm{b}}$ \\
$+5.0 \% \mathrm{Arg} \cdot \mathrm{HCl}+0.6 \% \mathrm{Lys} \cdot \mathrm{HCl}$ & $14,700 \pm 890^{\mathrm{b}}$ \\
\hline
\end{tabular}

a Mean $\pm \mathrm{SE}$. for four rats.

b Differences for control group were not significant $(p<0.05)$. 
$100 \mathrm{ml}$ of plasma, respectively). Similarly, the plasma tryptophan and methionine levels in animals that received excess tryptophan and methionine diets were extremely elevated (Trp, 190 and Met, $260 \mu$ mole per $100 \mathrm{ml}$ of plasma, respectively), but when lysine was supplemented to the diets, the corresponding amino acid levels of plasma decreased (Trp, trace and Met, $140 \mu$ mole per $100 \mathrm{ml}$ of plasma, respectively).

The effects of dietary arginine and lysine on the activity of liver arginase are shown in Table 2. The arginase activity of rats fed a diet containing excess arginine showed a tendency to increase as compared to the control, but the difference did not show any statistical significance. This result is essentially consistent with other reports $(7,9-11)$. The adequate supplement of lysine to the basal and the excess-arginine diet did not result in any appreciable effect on arginase activity.

\section{DISCUSSION}

The present studies demonstrate that the growth-depressing effect caused by excessive dietary arginine could be prevented by the supplementation of dietary lysine which is the first-limiting amino acid in a wheat gluten diet, but the adverse effects caused by the excessive addition of the other amino acids, such as tryptophan, phenylalanine, methionine or tyrosine, could not be reversed by supplemental lysine. Accordingly, it is clear that a) the adverse effects cause by excessive individual amino acids are not necessarily alleviated with the supply of the firstlimiting amino acid, and b) there exist a certain relationship between dietary arginine and lysine.

In relation to the situation of a), it is of interest that the extreme elevation of the corresponding plasma amino acid caused by the excess feeding of single amino acids were decreased by supplemental lysine, the most limiting amino acid, regardless of the fact that growth depressions were not counteracted.

As similar cases with the situation of $b$ ), several reports have shown that excess dietary lysine increases the requirement for arginine in chicks (12-17), guinea pigs (18) and rats (19). This specific lysine-arginine relationship has been interpreted as an antagonism between both amino acids (1, 12-14).

In contrast, little information has been accumulated about the effect of lysine supplement on excessive dietary arginine. O'DELL and SAVAGE (14) reported that the addition of $1.2 \%$ arginine to a sesame diet with limited lysine caused growth depression in chicks, but not when the diet was adequate in lysine. HILL et al. $(20,21)$ also noted in chicks a similar effect from excess arginine added to a diet first limited in lysine.

The present results confirm that an arginine-lysine antagonism of this type not only produces in the chick but also occurs in the rat under a particular dietary condition. In general, some factors such as intestinal absorption, renal reabsorption and metabolic alteration may be implicated as the possible mechanism. 
The mechanism by which excess lysine increases need for arginine in the chick has been extensively studied, and some investigators have suggested that the induction of kidney arginase by excess lysine is responsible in part for the possible mechanism $(15,16,22-24)$.

The present data in rats about the plasma arginine and lysine levels and liver arginase activity concerned with the mechanism did not furnished direct information as to the cause, that is, in the rat the supplementation of lysine to the excess arginine diet failed to produce appreciable effects on plasma lysine and arginine levels, and liver arginase activity. In contrast to this, in the chick, it was shown that when arginine is added to a excess-lysine diet, lysine level in plasma is markedly reduced $(22,23,25)$, and results in increased arginase activity of kidney $(15,16,23)$.

In any case, it is suggested that the addition of excess arginine to the diets in which lysine is the first-limiting amino acid in rats causes a reduction of lysine utilization and increases the need of lysine. Experiments are in progress to elucidate the cause of the arginine and lysine relationship in the rat.

We are grateful to Mrs. Taeko Aito for assistance with these experiments.

\section{REFERENCES}

1) Harper, A. E., Benevenga, N. J., and Wohlhueter, R. M., Physiol. Rev., 50, 428 (1970).

2) SAuberlich, H. E., J. Nutr., 75, 61 (1961).

3) Muramatsu, K., Odagiri, H., Morishita, S., and Takeuchi, H., J. Nutr., 101, 1117 (1971).

4) Harper, A. E., Becker, R. V., and Stucki, W. P., Proc. Soc. Exp. Biol. Med., 121, 695 (1966).

5) Muramatsu, K., Takeuchi, H., Funaki, Y., and Chisuwa, A., Agr. Biol. Chem., 36, 1269 (1972).

6) Muramatsu, K., Takeuchi, H., and Sakurai, K., J. Nutr. Sci. Vitaminol., 19, 277 (1973).

7) Muramatsu, K., Hirata, R., Kawakishi, S., and Ashida, K., Agr. Biol. Chem., 30, 466 (1966).

8) Morrison, A. B., Middleton, E. J., and Mclaughlan, J. M., Can. J. Biochem. Physiol., 39, 1675 (1961).

9) Auerbach, V. H. and Waisman, H. A., Proc. Soc. Exp. Biol. Med., 98, 123 (1958).

10) Schimke, R. T., J. Biol. Chem., 238, 1012 (1963).

11) Hutchinson, J. H., Jolley, R. L., and LabBy, D. H., Am. J. Clinical Nutr., 14, 291 (1964).

12) Jones, J. D., J. Nutr., 84, 313 (1964).

13) Sмith, R. E., J. Nutr., 95, 547 (1968).

14) O’Dell, B. L. and Savage, J. E., J. Nutr., 90, 364 (1966).

15) Jones, J. D., Petersburg, S. J., and Burnett, P. C., J. Nutr., 93, 103 (1967).

16) Austic, R. E. and Nesheim, M. C., J. Nutr., 100, 855 (1970).

17) Allen, N. K., BaKer, D. H., Scott, H. M., and Norton, H. W., J. Nutr., 102, 171 (1972).

18) O'Dell, B. L. and Regan, W. O., Proc. Soc. Exp. Biol. Med., 112, 336 (1963).

19) Jones, J. D., Wolters, R., and Burnett, P. C., J. Nutr., 89, 171 (1966).

20) Hill, D. C., Singh, J., and Ashton, G. C., Poultry Sci., 45, 554 (1966).

21) Hill, D. C. and ShaO, T. C., J. Nutr., 95, 63 (1968). 
22) Stutz, M. W., Savage, J. E., and O’Dell B. L., J. Nutr., 102, 449 (1972).

23) Wang S. H., Crosby L. O., and Nesheim, M. C., J. Nutr., 103, 384 (1973).

24) Nesheim, M. C., J. Nutr., 95, 79 (1968).

25) Zimmerman, R. A. and ScotT, H. M., J. Nutr., 87, 13 (1965). 